\title{
Safety of fentanyl initiation according to past opioid exposure among patients newly prescribed fentanyl patches
}

\author{
Kevin J. Friesen BSc (Pharm), Cornelius Woelk MD, Shawn Bugden MSc Pharm D
}

See also www.cmaj.ca/lookup/doi/10.1503/cmaj.160291

Competing interests: None declared.

This article has been peer reviewed.

Accepted: Feb. 3, 2016

Online: Apr. 4, 2016

Correspondence to:

Shawn Bugden,

shawn.bugden@

umanitoba.ca

CMAJ 2016. DOI:10.1503/ cmaj.150961

\begin{abstract}
Background: Although a convenient opioid delivery system, transdermal fentanyl patches have caused several deaths and resulted in safety warnings reminding prescribers that fentanyl patches should be prescribed only for patients who have adequate prior exposure to opioids. We conducted a longitudinal analysis of the safety of fentanyl initiation by examining past opioid exposure among patients newly prescribed fentanyl patches.
\end{abstract}

Methods: We identified all patients in the province of Manitoba who were newly prescribed fentanyl patches between Apr. 1, 2001, and Mar. 31, 2013. We converted all prior opioid use to oral morphine equivalents and determined the average daily dose in the 7-30 days before initial fentanyl patch use. Fentanyl initiation was considered unsafe if the patient's pre-fentanyl opioid exposure was below the recommended level.
Results: We identified 11063 patients who began using fentanyl patches during the study period. Overall, fentanyl initiation was deemed unsafe in $74.1 \%$ of cases because the patient's prior opioid exposure was inadequate. Women and patients 65 years of age and older were more likely than men and younger patients, respectively, to have inadequate prior opioid exposure ( $p<0.001$ for each comparison). The proportion of patients who had unsafe prescriptions for fentanyl patches decreased significantly over the study period, from $87.0 \%$ in 2001 to $50.0 \%$ in $2012(p<0.001)$.

Interpretation: The safety of fentanyl initiation improved over the study period, but still half of fentanyl patch prescriptions were written for patients with inadequate prior opioid exposure. Review of prior opioid exposure may be a simple but important way to improve the safe use of fentanyl patches.
$\mathrm{F}$ Tentanyl is a high-potency opioid with a strength 100 times that of morphine. ${ }^{1}$ Although available in a variety of forms, the most common form for outpatient use in Canada is the transdermal patch, which provides 3-day continuous delivery of the drug. Fentanyl was initially available in $25-$, 50-, 75- and $100-\mu \mathrm{g} / \mathrm{h}$ patches. A $12-\mu \mathrm{g} / \mathrm{h}$ patch was introduced in 2006 , recommended for dose titration rather than initiation. ${ }^{2}$ The fentanyl patch is a convenient non-oral delivery system preferred by patients that may have fewer adverse effects than other sustained-release oral formulations of opioids. ${ }^{3}$ As such, it has become a popular choice in the management of cancer-related and chronic non-cancer-related pain. ${ }^{4,5}$ The replacement of OxyContin with the tamper-resistant OxyNeo and the accompanying regulatory changes concerning long-acting oxycodone products have been associated with an increase in the use of fentanyl in some jurisdictions. ${ }^{6,7}$ Unfortunately, problematic fentanyl use is increasing. ${ }^{8,9}$ This rising level of use makes it an important time to assess safety issues related to the fentanyl patch.

One important safety issue, and a factor under the control of prescribers, is the recommendation that first-time users of the fentanyl patch have adequate prior exposure to opioids. ${ }^{2}$ Fentanyl patches are not suitable for opioid-naive patients. Only patients who have used the equivalent of $60 \mathrm{mg}$ of morphine per day for at least 1 week should be prescribed a $25-\mu \mathrm{g} / \mathrm{h}$ patch. ${ }^{2}$ Failure to adhere to this recommendation has been associated with adverse effects of opioid overdose, including depression of the central nervous system, flaccid skeletal muscles, hypotension, bradycardia, respiratory depression and death. ${ }^{2,3}$ Older patients are known to be at particular risk because of altered absorption and metabolism., ${ }^{2,10} \mathrm{~A}$ number of safety warnings and advisories have been issued to ensure that prescribers confirm patients have sufficient opioid tolerance before prescribing a fentanyl patch. ${ }^{11-20}$ 
A study of reported opioid-related deaths in the province of Ontario found that 57 (2.7\%) of the 3406 opioid-related deaths from 1991 to 2004 were related to fentanyl..$^{21}$ However, in this study, it is difficult to differentiate deaths related to problematic drug use or suicide from those associated with routine medical practice. There have been numerous case reports of deaths associated with inadequate opioid exposure before the initiation of fentanyl patches. ${ }^{11,12,14,17} \mathrm{~A}$ Health Canada review found $11.5 \%$ of the 52 fentanyl-related deaths examined were associated with fentanyl patch initiation. ${ }^{18}$ In a search of the Canada Vigilance Adverse Reaction Online Database for the period 1996-2015, after excluding cases related to the terms "intentional," "abuse," "suicide," "dependence" and "diversion," we found that health care professionals reported 284 deaths involving fentanyl patches to Health Canada.

We conducted a longitudinal analysis of the safety of fentanyl initiation by examining prior opioid exposure among patients newly prescribed fentanyl patches. The objective was to assess the potential influence of the various warnings and safety bulletins related to safe fentanyl prescribing and to determine the current level of risk in the Manitoba population.

\section{Methods}

We examined the safety of fentanyl patch initiation among patients 18 years of age and older in the fiscal years from Apr. 1, 2001, to Mar. 31, 2013. We used data from the Population Health Research Data Repository maintained by the Manitoba Centre for Health Policy. Prescription records were obtained from the province's Drug Programs Information Network database. This centralized system is used to process all outpatient prescriptions and submit claims to the province's drug benefits plan (Pharmacare) and to third-party insurers. Using these prescription records, we examined pre-fentanyl opioid use to estimate whether the recommended guidelines for adequate opioid tolerance for safe fentanyl patch initiation had been met.

We constructed a cohort consisting of all patients who had 1 or more prescriptions for transdermal fentanyl filled. We excluded patients who had fentanyl prescriptions filled in the first 90 days of the study period, to avoid misclassifying prevalent use as fentanyl initiation. We used administrative data from hospital discharge abstracts to exclude patients admitted to hospital in the 30 days before their first fentanyl prescription, because no data were available on opioid use in hospital.
To determine opioid exposure before fentanyl patch use, we examined all opioid prescriptions filled more than 90 days before the start of fentanyl. We converted opioid doses to morphine equivalents using standard opioid conversion tables. ${ }^{22} \mathrm{We}$ calculated daily doses by multiplying the number of dispensed tablets by the strength of the morphine equivalent and dividing by the days supplied. For patients with concurrent opioid prescriptions, we summed the contributions from each prescription over the days of overlap. We calculated the average daily doses for the 7 , 14,30 and 60 days preceding the first fentanyl prescription and took the highest average daily dose. We classified fentanyl initiation as safe if the pre-fentanyl opioid daily dose met or exceeded the dosing guidelines in the manufacturer's product monograph. ${ }^{2}$

We conducted a sensitivity analysis in which we defined fentanyl initiation as safe if there was any opioid use in the 60 days before the first fentanyl prescription. Patients with no prior exposure were considered to be fully opioid naive and at greatest risk of an adverse effect from fentanyl use. In addition, to ensure that most patients were not clustered close to the threshold of adequate opioid exposure, we stratified patients who had unsafe fentanyl initiation by the percentage of recommended opioid dose they received before starting fentanyl.

Use of the $12-\mu \mathrm{g} / \mathrm{h}$ fentanyl patch was also examined to explore whether it was for dose titration or for fentanyl initiation. Each patient's first prescription for the $12-\mu \mathrm{g} / \mathrm{h}$ patch was classified as initiation if it was their first ever fentanyl patch, and as titration if otherwise.

\section{Statistical analysis}

We performed all analyses using SAS software (version 9.4, SAS Institute). Univariate analysis was used to summarize our data. The proportion of prescriptions that were considered safe fentanyl initiations was calculated overall, by year, by sex and by age group $(<65,65-74,75-84$ and $\geq 85 \mathrm{yr}$ ). The $\chi^{2}$ test was used to examine the proportion of safe initiations for the categorical variables of sex, age group ( $\geq 65 \mathrm{v}$. $<65 \mathrm{yr}$ ) and study year (first v. last). Rates of safe initiation were tabulated for each study year and, separately, by patient age (in years) at the time fentanyl was started. Ordinary linear regression models were constructed for each of these sets of data to determine the significance of trends present.

\section{Results}

From Apr. 1, 2001, to Mar. 31, 2013, we identified 267958 prescriptions for transdermal fentanyl patches dispensed to 17102 distinct pa- 
tients. The 744 patients given prescriptions in the first 3 months of the study were excluded as potentially prevalent users. We also excluded another 5295 patients admitted to hospital in the 30 days before fentanyl initiation. The final cohort of 11063 patients included more women than men, and more older people ( $\geq 65 \mathrm{yr}$ ) than younger patients (Table 1). The initial dose most commonly prescribed was $25 \mu \mathrm{g} / \mathrm{h}$; in $18.4 \%$ of cases, the initial dose was $50 \mu \mathrm{g} / \mathrm{h}$ or higher.

Fentanyl patch initiation was deemed unsafe in most cases overall, with $74.1 \%$ of new prescriptions written for patients with inadequate prior opioid exposure (Table 2). In $33.4 \%$ of cases, a combined formulation of acetaminophen/ codeine or acetaminophen/oxycodone was the only opioid prescribed before the start of fentanyl (Table 1). Unsafe fentanyl initiation decreased over the study period, from $87.0 \%$ of prescriptions in 2001 to $50.0 \%$ in 2012 ( $p<0.001)$. The decrease was greater among men than among

\begin{tabular}{|c|c|}
\hline Characteristic & $\begin{array}{c}\text { No. }(\%) \\
n=11063\end{array}$ \\
\hline \multicolumn{2}{|l|}{ Sex } \\
\hline Female & $6884(62.2)$ \\
\hline Male & $4179(37.8)$ \\
\hline \multicolumn{2}{|l|}{ Age group, yr } \\
\hline$\leq 64$ & $4692(42.4)$ \\
\hline $65-74$ & $1894(17.1)$ \\
\hline $75-84$ & $2500(22.6)$ \\
\hline$\geq 85$ & 1977 (17.9) \\
\hline \multicolumn{2}{|l|}{$\begin{array}{l}\text { Initial dose of fentanyl } \\
\text { patch, } \mu \mathrm{g} / \mathrm{h}\end{array}$} \\
\hline 12 & $1293(11.7)$ \\
\hline 25 & $7739(70.0)$ \\
\hline 50 & $1459(13.2)$ \\
\hline 75 & $363 \quad(3.3)$ \\
\hline 100 & $209 \quad(1.9)$ \\
\hline \multicolumn{2}{|l|}{ Prior opioid exposure* } \\
\hline Single-entity LA opioid & $2956(26.7)$ \\
\hline Single-entity IR opioid & $1889(17.1)$ \\
\hline Oxycodone/acetaminophen & $1289(11.7)$ \\
\hline Codeine/acetaminophen & $2406(21.7)$ \\
\hline No exposure & $2523(22.8)$ \\
\hline \multicolumn{2}{|c|}{$\begin{array}{l}\text { Note: IR = immediate release, } L A=\text { long acting. } \\
{ }^{*} \text { Mutually exclusive groups of patients categorized by } \\
\text { highest to lowest level of opioid used in the } 90 \text { days } \\
\text { preceding the first fentanyl patch prescription (highest = } \\
\text { single-entity LA opioid; lowest = codeine/acetaminophen } \\
\text { combination). }\end{array}$} \\
\hline
\end{tabular}

women (by $40.4 \%$ v. $34.3 \%$; $p<0.001$ ), and among older patients than among those less than 65 years old (by $37.7 \%$ v. $33.0 \%$; $p<0.001$ ).

In the linear regression analysis in which the safety of fentanyl initiation was examined over time, we found a significant increase in the level of safe prescribing over the study period. The percent of new prescriptions that met the recommended pre-fentanyl opioid exposure levels increased by $3.9 \%$ each year $(95 \%$ confidence interval [CI] 3.4\%-4.5\%). In the linear regression analysis by patient age, we found a significant trend toward decreased levels of safety with increasing age. Each additional year of life was associated with a $0.39 \%$ decrease in the mean rate of safe initiation (95\% CI $0.32 \%-0.45)$.

In the sensitivity analysis in which fentanyl initiation was considered safe if any amount of opioid was used in the 60 days before the start of fentanyl, $26.3 \%$ of the prescriptions were to fully opioid-naive patients. Again, older patients were at greater risk than those less than 65 years of age $(32.3 \%$ v. $18.1 \% ; p<0.001)$. The level of fentanyl patch initiation among opioid-naive patients fell significantly over time, from $35.3 \%$ of all fentanyl starts in 2001 to $15.7 \%$ in 2012 $(p<0.001)$. The levels of fentanyl initiation among the other patients, stratified by percent of recommended pre-fentanyl opioid dose, are shown in Figure 1.

The association between prior opioid exposure and the starting dose of fentanyl patch is examined in greater detail in Table 3. Although higher starting doses of fentanyl patch were generally associated with greater prior opioid exposure, all strengths of patch were at times initiated without previous opioid exposure. When we looked at the pattern of use for the $12-\mu \mathrm{g} / \mathrm{h}$ fentanyl patch, we found that, in the first year of its use in Canada, $54 \%$ of first uses were for initiation rather than titration; by the end of the study period, this value increased to $65.5 \%$ of first uses. Because the $12-\mu \mathrm{g} / \mathrm{h}$ patch has less opioid than the $25-\mu \mathrm{g} / \mathrm{h}$ patch, it is easier to achieve adequate opioid tolerance with this strength of patch $(30 \mathrm{mg} \mathrm{v} .60 \mathrm{mg}$ morphine equivalent per day). Even at this lower threshold, only $43.5 \%$ $(n=563)$ of the 1293 initial prescriptions for the $12-\mu \mathrm{g} / \mathrm{h}$ fentanyl patch would be considered safe. Of these safe starts, $54.7 \%(n=308)$ would have been classified as unsafe if the $25-\mu \mathrm{g} / \mathrm{h}$ patch had been prescribed initially.

\section{Interpretation}

Our analysis showed that the level of safety of fentanyl prescribing improved over the study period. However, by the end of the study, still 
only half of the initial prescriptions were issued to patients with adequate prior exposure to opioids. The sensitivity analysis of the distribution of patients relative to the percentage of the recommended pre-fentanyl opioid exposure allowed us to examine the different levels of prior opioid exposure, with the presumption that doses close to the recommended level would be associated with a lower risk of adverse effects. However, at the end of the study period, $15.7 \%$ of patients in the sensitivity analysis were receiving fentanyl patches without exposure to opioids of any kind in the 60 days before fentanyl was started. Of particular concern, patients 65 and older, who may be at the greatest risk, had higher levels of unsafe fentanyl initiation than younger patients. In the overall study population, there was considerable improvement, with a $37.0 \%$ decrease in unsafe prescribing over the study period. The use of the $12-\mu \mathrm{g} / \mathrm{h}$ patch for fentanyl initiation increased over the study period. Although its use may reduce the risk of adverse effects, it does not eliminate the need for prior opioid exposure.

Absorption of fentanyl from patches varies widely between patients..$^{23}$ This variation, along with exposure of the patch to heat, improper use of the patch, use of multiple patches and a variety of other factors, combine with inadequate opioid exposure in cases that result in death. ${ }^{14,15,24,25}$

The systematic study of the quality of fentanyl patch prescribing has been limited. European studies of administrative data used different definitions of opioid tolerance but produced comparable results. ${ }^{26,27}$ The largest study was in Germany in 2004-2006 and found that $84.5 \%$ of fentanyl starts were in opioid-naive patients. ${ }^{26}$ The authors defined opioid naive as receiving no high-potency opioids in the 3 months before fentanyl patch initiation. As in our study, they found a higher risk of unsafe fentanyl initiation among women than among men and a decreasing level of safe prescribing with increasing age. A small study in the United States examined fentanyl patch prescribing among nursing home residents. ${ }^{10}$ As in our study, women and older adults were at increased risk of fentanyl patches and other long-acting opioids being started without prior exposure to short-acting opioids. In a recent US intervention study in a regional medical centre, McEvoy and colleagues ${ }^{28}$ made use of electronic medical records to remind prescribers of the need for patients to be given $60 \mathrm{mg}$ of morphine or equivalent before prescribing fentanyl patches. Before this intervention, only $46.7 \%$ of patients had received adequate opioid doses when fentanyl was pre- scribed. After the intervention, the value increased to $75.6 \%$, which suggests that relatively simple interventions may substantially improve the safety of fentanyl prescribing. Despite the relatively low level of safe prescribing found in our study, we believe our results are generalizable, because similar levels of safety have been found in Europe and the United States.

Table 2: Safety of fentanyl initiation at the start and end of the study period, by sex and age

\begin{tabular}{|lccc|}
\hline & \multicolumn{3}{c|}{$\begin{array}{c}\text { (no.) of patients with unsafe } \\
\text { fentanyl initiation* }\end{array}$} \\
\cline { 2 - 4 } Characteristic & $\begin{array}{c}2001 \\
n=866\end{array}$ & $\begin{array}{c}2012 \\
n=574\end{array}$ & $\begin{array}{c}\text { Overall } \\
n=11063\end{array}$ \\
\hline Sex & & & \\
\hline Female & $87.4(501 / 573)$ & $53.1(178 / 335)$ & $76.3(5253 / 6884)$ \\
\hline Male & $86.0(252 / 293)$ & $45.6(109 / 239)$ & $70.4(2943 / 4179)$ \\
\hline Age group, yr & & & \\
\hline$\leq 64$ & $79.0(233 / 295)$ & $45.9(119 / 259)$ & $66.1(3100 / 4692)$ \\
\hline $65-74$ & $86.3(126 / 146)$ & $41.7(48 / 115)$ & $72.7(1377 / 1894)$ \\
\hline $75-84$ & $89.4(210 / 235)$ & $52.3(58 / 111)$ & $81.6(2039 / 2500)$ \\
\hline$\geq 85$ & $96.8(184 / 190)$ & $69.7(62 / 89)$ & $85.0(1680 / 1977)$ \\
\hline All & $87.0(753 / 866)$ & $50.0(287 / 574)$ & $74.1(8196 / 11063)$ \\
\hline $\begin{array}{l}\text { *Unsafe = fentanyl patch newly prescribed to patient without adequate prior exposure to } \\
\text { opioids. }\end{array}$ & & \\
\hline
\end{tabular}

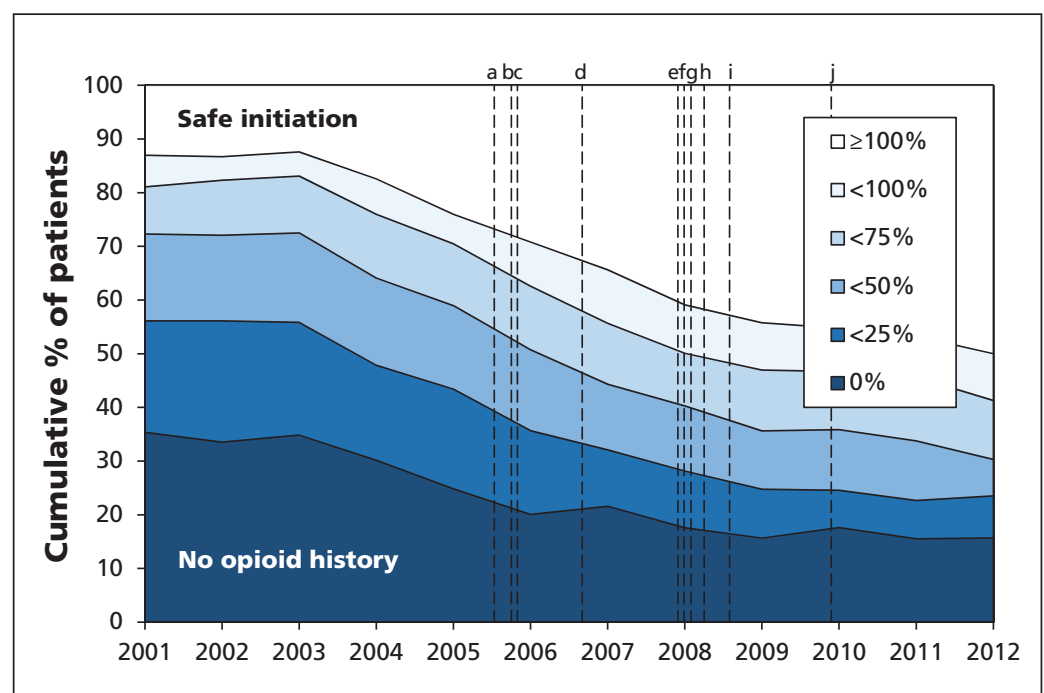

Figure 1: Proportion of patients newly prescribed fentanyl patches, 2001-2012, by level of previous opioid exposure (\% of recommended opioid dose in the 60 days before fentanyl initiation). Previous opioid use ranged from $0 \%$ (no opioid history) to $\geq 100 \%$ (safe initiation of fentanyl). The vertical dashed lines represent when warnings or advisories were issued by the US Food and Drug Administration ( $a$ and $f),{ }^{11,12}$ Health Canada (b and $\left.i\right),{ }^{13,18}$ the Institute for Safe Medication Practices Canada (d, e, $h$ and $j)^{14-17}$ and professional journals (c and g). ${ }^{19,20}$ 
Table 3: Distribution of patients according to initial fentanyl dose and prior opioid exposure

\begin{tabular}{|lcccccc|}
\hline & \multicolumn{5}{c|}{ Initial fentanyl patch dose, $\mu \mathrm{g} / \mathrm{h}$; no. (\%) of patients* } \\
\cline { 2 - 7 } $\begin{array}{l}\text { Prior opioid exposure, } \\
\text { mg/d of oral morphine } \\
\text { equivalent }\end{array}$ & $\begin{array}{c}12 \\
n=1293\end{array}$ & $\begin{array}{c}25 \\
n=7739\end{array}$ & $\begin{array}{c}50 \\
n=1459\end{array}$ & $\begin{array}{c}75 \\
n=363\end{array}$ & $\begin{array}{c}100 \\
n=209\end{array}$ & $n=11063$ \\
\hline No exposure & $301(10.4)$ & $2276(78.3)$ & $248(8.5)$ & $51(1.8)$ & $31(1.1)$ & 2907 \\
\hline $1-29$ & $429(13.9)$ & $2287(73.9)$ & $315(10.2)$ & $47(1.5)$ & $16(0.5)$ & 3094 \\
\hline $30-59$ & $308(15.7)$ & $1382(70.4)$ & $223(11.4)$ & $38(1.9)$ & $13(0.7)$ & 1964 \\
\hline $60-179$ & $215(10.3)$ & $1412(67.6)$ & $358(17.1)$ & $77(3.7)$ & $27(1.3)$ & 2089 \\
\hline $180-269$ & $18(4.4)$ & $191(46.7)$ & $134(32.8)$ & $43(10.5)$ & $23(5.6)$ & 409 \\
\hline $270-359$ & $9(4.8)$ & $71(37.8)$ & $57(30.3)$ & $40(21.3)$ & $11 \quad(5.9)$ & 188 \\
\hline$\geq 360$ & $13(3.2)$ & $120(29.1)$ & $124(30.1)$ & $67(16.3)$ & $88(21.4)$ \\
\hline *Percentages are based on row totals. Values in blue screened cells represent inadequate prior opioid exposure. & 412 \\
\hline
\end{tabular}

\section{Limitations and strengths}

This study has a number of important limitations. We estimated prior opioid use from pharmacy dispensing data for opioid prescriptions. Patients may not have used the medications, or they may have used more than initially prescribed based on verbal instruction from the prescriber for dose adjustment. However, the assumption of use based on pharmacy dispensations is common in administrative data studies. ${ }^{29}$ We were not able to capture opioid medication use prescribed outside of the province. The study is also limited by not examining outcomes of fentanyl prescribing. We assessed the safety of fentanyl initiation as defined by the product monograph and safety warnings. The rate at which unsafe prescribing, as defined by dosing recommendations and warnings, translates into actual negative outcomes for patients is unknown, but case reports have shown that they occur. ${ }^{14-16,24}$

Despite these limitations, our study has a number of strengths. Our use of a fully linked population-level database leaves us confident that we captured most instances of community prescribing of opioids. The 12-year duration of the study also allowed us to examine the safety of fentanyl prescribing before and after the release of safety warnings. We also used multiple definitions of opioid tolerance and used the most conservative result in our assessment of the safety of fentanyl prescribing.

\section{Conclusion}

Considerable attention and effort have been placed into making prescribers aware of the need to ensure adequate opioid tolerance before prescribing fentanyl patches. Although we found evidence that the safety of fentanyl prescribing improved, by the end of the study period, still half of patients prescribed fentanyl patches had inadequate prior exposure to opioids. Special attention should be paid to older patients, who are at greatest risk of adverse outcomes but had the lowest level of safe prescribing. Opioid prescribing generally, and fentanyl patch prescribing in particular, has a number of inherent risks, many of which may be difficult to control fully. Ensuring adequate opioid tolerance before prescribing a fentanyl patch is one way this risk can be controlled by the prescriber.

\section{References}

1. Skaer TL. Dosing considerations with transdermal formulations of fentanyl and buprenorphine for the treatment of cancer pain. J Pain Res 2014;7:495-503.

2. DuragesicMAT [product monograph]. In: Compendium of Pharmaceuticals and Specialties. Toronto: Canadian Pharmacists Association; 2014

3. Tassinari D, Sartori S, Tamburini E, et al. Transdermal fentanyl as a front-line approach to moderate-severe pain: a meta-analysis of randomized clinical trials. J Palliat Care 2009;25:172-80.

4. Ripamonti C, Fagnoni E, Campa T, et al. Is the use of transdermal fentanyl inappropriate according to the WHO guidelines and the EAPC recommendations? A study of cancer patients in Italy. Support Care Cancer 2006;14:400-7.

5. Fischer B, Jones W, Krahn M, et al. Differences and over-time changes in levels of prescription opioid analgesic dispensing from retail pharmacies in Canada, 2005-2010. Pharmacoepidemiol Drug Saf 2011;20:1269-77.

6. National Prescription Drug Utilization Information System. Utilization of prescription opioids in Canada's public drug plans, 2006/07 to 2012/13. Ottawa: Patented Medicine Prices Review Board; 2014

7. Gomes T, Mamdani MM, Paterson JM, et al. Trends in high-dose opioid prescribing in Canada. Can Fam Physician 2014;60:826-32.

8. Firestone M, Goldman B, Fischer B. Fentanyl use among street drug users in Toronto, Canada: behavioural dynamics and public health implications. Int J Drug Policy 2009;20:90-2.

9. Deaths involving fentanyl in Canada, 2009-2014. In: Bulletin CCENDU. Ottawa: Canadian Centre on Substance Abuse; 2015. Available: www.ccsa.ca/Resource\%20Library/CCSA-CCENDU -Fentanyl-Deaths-Canada-Bulletin-2015-en.pdf (accessed 2016 Jan. 18).

10. Dosa DM, Dore DD, Mor V, et al. Frequency of long-acting opioid analgesic initiation in opioid-naive nursing home residents. J Pain Symptom Manage 2009;38:515-21.

11. Duragesic (fentanyl transdermal system). Silver Spring (MD): US Food and Drug Administration; 2005. Available: www.fda.gov/ Safety/MedWatch/SafetyInformation/SafetyAlertsforHuman MedicalProducts/ucm151138.htm (accessed 2015 Aug. 14). 
12. FDA issues second safety warning on fentanyl skin patch: deaths and serious injuries from improper use. Silver Spring (MD): US Food and Drug Administration; 2007. Available: www.fda.gov/ NewsEvents/Newsroom/PressAnnouncements/2007/ucm109046. htm (accessed 2015 Aug. 14).

13. Important safety information on Duragesic (fentanyl transdermal system). Ottawa: Health Canada; 2005. Available: healthy canadians.gc.ca/recall-alert-rappel-avis/hc-sc/2005/14319a-eng.php (accessed 2015 Aug. 14).

14. Analysis of international findings from incidents involving fentanyl transdermal patches. ISMP Canada Safety Bulletin 2009;9(10):1-4. Available: www.ismp-canada.org/download/ safetyBulletins/ISMPCSB2009-10-AnalysisOfInternational FindingsFromIncidentsInvolvingFentanylTransdermal.pdf (accessed 2015 Aug. 1).

15. Drug interaction incident with HIV post-exposure prophylaxis ISMP Canada Safety Bulletin 2008;8(3):1-2. Available: www. ismp-canada.org/download/safetyBulletins/ISMPCSB2008 -03HIVPEP.pdf (accessed 2015 Aug. 1).

16. Fentanyl patch linked to another death in Canada. ISMP Canada Safety Bulletin 2007;7(5):1-2. Available: www.ismp-canada.org/ download/safetyBulletins/ISMPCSB2007-05Fentanyl.pdf (accessed 2015 Aug. 1)

17. Transdermal fentanyl: a misunderstood dosage form. ISMP Canada Safety Bulletin 2006;6(5):1-4. Available: www.ismp-canada. org/download/safetyBulletins/ISMPCSB2006-05Fentanyl.pdf (accessed 2015 Aug. 1).

18. McMorran M, Longo M. Fentanyl transdermal patch and fatal adverse reactions. Can Adverse Reaction Newsl [Health Canada] 2008;18(3):1-2. Available: www.hc-sc.gc.ca/dhp-mps/alt formats/pdf/medeff/bulletin/carn-bcei_v18n3-eng.pdf (accessed 2015 Aug. 1).

19. Wichman K, David U. Overdose a risk of transdermal patch in diverse settings. Can Pharm J 2005;138:65-6.

20. Greenall J, Koczmara C, Cheng R, et al. Safety issues with fentanyl patches require pharmaceutical care. Can J Hosp Pharm 2008;61:57-9.

21. Dhalla IA, Mamdani MM, Sivilotti MLA, et al. Prescribing of opioid analgesics and related mortality before and after the introduction of long-acting oxycodone. CMAJ 2009;181:891-6.

22. Canadian guideline for safe and effective use of opioids for chronic non-cancer pain. Part B: recommendations for practice. Hamilton: National Opioid Use Guideline Group; 2010. Available: nationalpaincentre.mcmaster.ca/documents/opioid_guideline part b v5 6.pdf (accessed 2015 Aug. 1).

23. Lane ME. The transdermal delivery of fentanyl. Eur J Pharm Biopharm 2013;84:449-55
24. Moon JM, Chun BJ. Fentanyl intoxication caused by abuse of transdermal fentanyl. J Emerg Med 2011;40:37-40.

25. Martin TL, Woodall KL, McLellan BA. Fentanyl-related death in Ontario, Canada: toxicological findings and circumstances of death in 112 cases (2002-2004). J Anal Toxicol 2006;30:603-10.

26. Garbe E, Jobski K, Schmid U. Utilisation of transdermal fentanyl in Germany from 2004 to 2006. Pharmacoepidemiol Drug Saf 2012;21:191-8.

27. Breekveldt-Postma NS, Penning-van Beest FJA, Herings RMC Utilisation pattern of fentanyl transdermal system in The Netherlands. Pharmacoepidemiol Drug Saf 2005;14:129-34.

28. McEvoy T, Moore J, Generali J. Inpatient prescribing and monitoring of fentanyl transdermal systems: adherence to safety regulations. Hosp Pharm 2014;49:942-9.

29. Sattler ELP, Lee JS, Perri M. Medication (re)fill adherence measures derived from pharmacy claims data in older Americans: a review of the literature. Drugs Aging 2013;30:383-99.

Affiliations: College of Pharmacy (Friesen, Bugden) Faculty of Health Sciences, University of Manitoba; Department of Family Medicine (Woelk), College of Medicine, Faculty of Health Sciences, University of Manitoba, Winnipeg, Man

Contributors: Cornelius Woelk and Shawn Bugden were involved in the study conception. Kevin Friesen and Shawn Bugden were involved in the study design, and the acquisition, analysis and interpretation of data. Kevin Friesen and Shawn Bugden drafted the manuscript; all of the authors revised and critically evaluated the manuscript, approved the final version to be published and agreed to act as guarantors of the work.

Funding: This study was funded by a research grant (no. G00316138) from the University of Manitoba.

Acknowledgement: The authors acknowledge the Manitoba Centre for Health Policy for use of data contained in the Population Health Research Data Repository (HIPC file no. 2012/2013-08). The results and conclusions are those of the authors, and no official endorsement by the Manitoba Centre for Health Policy, by Manitoba Health, Healthy Living and Seniors, or by other data providers is intended or should be inferred. The authors thank Mara Creek for valuable review of the manuscript.

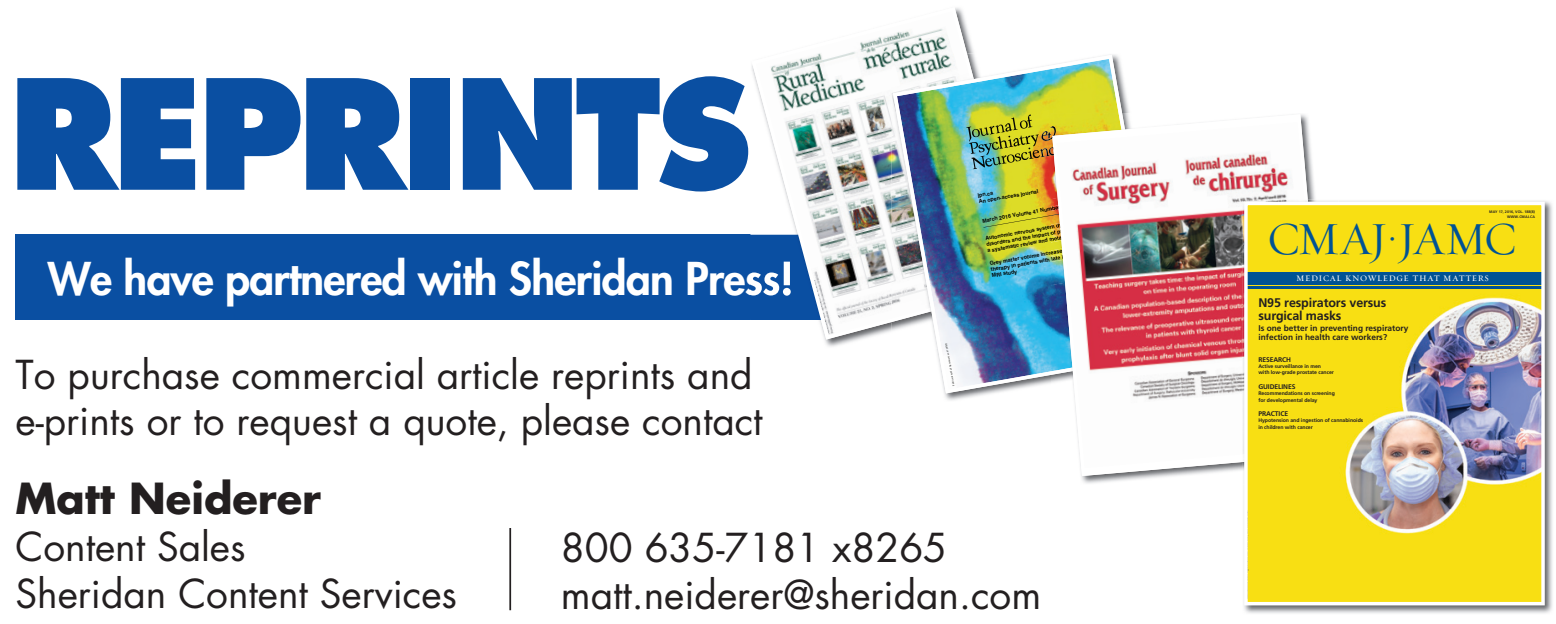

